\title{
A Model of Destructive Entrepreneurship: Insight for Conflict and Postconflict Recovery
}

Journal of Conflict Resolution 57(I) 20-40 (C) The Author(s) 2012 Reprints and permission: sagepub.com/journalsPermissions.nav DOI: I0.1 I77/00220027/2464853 jcr.sagepub.com (9) SAGE

\author{
Sameeksha Desai ', Zoltan J. Acs ${ }^{2}$, and Utz Weitzel ${ }^{3}$
}

\begin{abstract}
The research on entrepreneurship as an economic phenomenon often assumes its desirability as a driver of economic development and growth. However, entrepreneurial talent can be allocated among productive, unproductive and destructive activities. This allocation has important implications in the developing world, particularly for countries hosting conflict or recovering from conflict. The allocation of entrepreneurship is theorized as driven by institutions. Although the trade-off between productive and unproductive entrepreneurship has been examined, destructive entrepreneurship has been largely ignored. We build from existing theory and define destructive entrepreneurship as wealth destroying. We propose three assumptions to develop a model of destructive entrepreneurship that presents the mechanisms through which entrepreneurial talent behaves in this manner. We present four key propositions on the nature and behavior of destructive entrepreneurship. We conclude by identifying research agendas and policy streams, with a focus on relevance to conflict and postconflict recovery.
\end{abstract}

\section{Keywords}

destructive entrepreneurship, unproductive, productive, allocation, rent-seeking, incentives, institutions, conflict, postconflict recovery

\footnotetext{
I Indiana University, School of Public and Environmental Affairs, Bloomington, IN, USA

${ }^{2}$ George Mason University, School of Public Policy, Arlington, VA, USA

${ }^{3}$ Radboud University Nijmegen, Institute for Management Research, Nijmegen, the Netherlands

Corresponding Author:

Sameeksha Desai, Indiana University, I3I5 E. 10 $0^{\text {th }}$ Street, Bloomington, IN 47405, USA.

Email: desai@indiana.edu
} 
The allocation of a resource affects the quality and extent of its contribution to the economy. As a resource, entrepreneurial talent affects the nature of economic activities and their subsequent implications for growth (see Douhan and Henrekson, 2008a). Attempts to shed light on the dynamics of entrepreneurial talent have come overwhelmingly from empirical perspectives, while less attention has been paid to its theoretical foundations. Empirical approaches tend to build from an assumption that entrepreneurship should be encouraged because of universal positive effects on employment, wealth creation, and innovation.

However, the existence of entrepreneurial talent itself is not enough. Entrepreneurs do not consider externalities or societal effects when they work to increase wealth, power, and prestige (Baumol 1990). Entrepreneurial talent is allocated to activities "with the highest private returns, which need not have the highest social returns" (Murphy, Shleifer, and Vishny 1991, 506). It is not possible to make inferences about externalities or overall social welfare effects. Universal "goodness" of entrepreneurship is not implicit and activities can certainly exert questionable or undesirable effects. Entrepreneurial talent can thus be allocated among a range of choices with varying effects.

The determinants of this process in a country or region have roots in institutions. Baumol (1990) theorizes the allocation of entrepreneurship as occurring among productive, unproductive, and destructive forms. He considers productive entrepreneurship as wealth-creating activity and unproductive entrepreneurship as redistributive activity. Assuming a generally substantial role for entrepreneurs across societies, he argues that entrepreneurial behavior responds to incentives (i.e, "the rules of the game") set by institutions, which are subject to change in any given institutional context. Similarly, Murphy, Shleifer, and Vishny (1991) distinguish between entrepreneurship and rent-seeking and that find rent-seeking rewards talent more than entrepreneurship in many contexts. In their approach, the trade-off is between entrepreneurship (starting firms that innovate and foster growth) and rent-seeking (redistributing wealth and reducing growth). Murphy, Shleifer, and Vishny (1991, 1993) treat entrepreneurship as distinct from rent-seeking; we favor a breakdown of entrepreneurship to explicitly avoid treating it as universally desirable. Both Baumol (1990) and Murphy, Shleifer, and Vishny (1991) are consistent in their treatment of incentive structures driving entrepreneurial choices. ${ }^{1}$ However, Murphy, Shleifer, and Vishny (1991) make an additional, critical point: That increasing returns to ability will force entrepreneurship and rent-seeking activities to compete for the same talent.

If the same actor could be engaged in such different entrepreneurial activities, then the mechanisms through which talent is allocated have important implications for economic outcomes. Some approaches treat rent-seeking (or unproductive entrepreneurship) as a worst-case condition that threatens productive entrepreneurship (for related work on rent-seeking, see also Nunn 2007; Grossman and Kim 1995). Murphy, Shleifer, and Vishny (1993) find that rent-seeking negatively affects growth through bureaucratic agents that stifle innovation. These effects prevent the 
Journal of Conflict Resolution 57(I)

proverbial "pie" from growing. Baumol's discussion of destructive entrepreneurship acknowledges the existence of a truly negative type of entrepreneurial activity. However, existing perspectives do not fully address shrinking of the pie-that is, what happens when entrepreneurial activity does not create or redistribute wealth but actually destroys it. Bhagwati's (1982) conception of directly unproductive, profitseeking (DUP) activities comprises rent-seeking as a subset and also introduces the important consideration of reducing welfare. We extend Baumol's discussion of the allocation of entrepreneurship in a simple and intuitive manner, to define destructive entrepreneurship as wealth destroying (such as the destruction of inputs for production activities).

Theoretical work on destructive entrepreneurship is noticeably absent from the literature. Current understanding of entrepreneurship is thus incomplete, rendering existing knowledge inadequate. Empirical interest in the allocation of entrepreneurship is growing (see, for example, Bowen and de Clerq 2008; Sobel 2008; Weitzel et al. 2010; Urbig et al. 2012) yet is still a relatively young area of investigation. We argue that a solid theoretical foundation is necessary to inform the development of rigorous empirical work, as with any other field of research. This is particularly important because of the direct implications for public policies and economic development. ${ }^{2}$

In this article, we advance the literature by proposing a model of destructive entrepreneurship. We use three important assumptions in our approach. First, we assume constant supply but varying allocation of entrepreneurial talent. Second, we assume that entrepreneurs can diminish inputs for production. Third, we assume heterogeneity of entrepreneurs. Our assumptions allow us to shift the focus from the productive/unproductive trade-off to destructive entrepreneurship.

In the next section, we present our assumptions and derive our model of destructive entrepreneurship. In the third section, we briefly discuss incentives and the problems of endogenous institutions in directing entrepreneurship. We present implications, outline key promising areas for further research, and conclude in the fourth section.

\section{A Model of Destructive Entrepreneurship}

\section{Assumptions}

We begin with three assumptions:

Assumption 1: The supply of entrepreneurial talent is constant but varies in its allocation.

We accept Baumol's proposition that the supply of entrepreneurs remains relatively constant and assume that the same proportion of people will be entrepreneurs, but their chosen activities can change. It is necessary to restate that entrepreneurship is not by nature positive and that entrepreneurs operate to maximize utility. We view rentseeking within the spectrum of entrepreneurial activity. Therefore, we assume entrepreneurs are driven by rents, and this generally holds true across the range of allocation. 
Assumption 2: Entrepreneurs are able to diminish inputs for production.

Classic principal-agent models on externally financed ventures assume that entrepreneurs are able to divert some of the venture's proceeds for private use (e.g., Tirole 2006). In these models, the cash flows of a venture can be diverted, but the productive assets remain untouched. We include the possibility that entrepreneurs can also misappropriate the productive inputs of a venture, effectively destroying the possibility to generate revenues at all. This can be done in two ways. First, destructive entrepreneurs can convince capitalists to invest into a venture and then find ways to steal or misappropriate the committed funds or the fixed assets purchased with them. Second, destructive entrepreneurs can simply raid any productive assets in an economy, such as sources for production in extractive industries. Thus, instead of convincing the capitalist to fund a productive venture, destructive entrepreneurs devise ways to forcefully steal the assets from capitalists, irrespective of the latter's investment decision. We analyze both types of destructive entrepreneurs in our model, allowing us to explain a range of activities occurring during conflicts and other forms of political instability as well some criminal activity.

\section{Assumption 3: Entrepreneurs are heterogeneous.}

Even if all entrepreneurs are born with exactly the same entrepreneurial talent, it is likely that they differ in many other aspects. This heterogeneity can result from varying degrees of training or skills, different levels of patience (discount factors), endowments of other talents, or from differences in access to markets or to facilitating networks. This heterogeneity may not influence the entrepreneurial talent per se but affects the magnitude and choice of possible returns once the talent is employed (for a related discussion, refer to Murphy, Shleifer, and Vishny 1991). In lessdeveloped economies, additional training, initial endowments and the urgency for quick returns play a particularly important role in the success of entrepreneurial activities, as well as constitute dimensions with significant heterogeneity and polarization. To integrate this aspect, we assume that entrepreneurs expect different payoffs from their activities. For simplicity, we model this assumption by specifying different levels of patience (discount factors) for entrepreneurs, but other characteristics that motivate heterogeneous project returns are also possible.

Together, these three assumptions shift the lens from productive and unproductive entrepreneurship to destructive entrepreneurship.

\section{Framework}

The basic framework for the model of destructive entrepreneurship builds upon the work of Tirole (2006), who employs a simplified version of the model by Holmstrom and Tirole (1997). The starting point of the model is that any entrepreneurial opportunity will require a fixed investment $I$, which the entrepreneur cannot fully finance internally. Let us assume the entrepreneur would like to exploit an opportunity. 
Journal of Conflict Resolution 57(I)

Initially, the entrepreneur has assets $A<I$. Since he must access external capital, he will approach a capitalist for the amount $I-A>0 .{ }^{3}$ If undertaken, the activity will yield a verifiable income $R>0$.

Based on this framework, we assume that the entrepreneur has two types $\delta_{i}$, which can be interpreted as different levels of impatience. This reflects the notion of heterogeneity between entrepreneurs. The capitalist believes that the types $\delta_{i}$ are independent and only have two possible values: $\delta_{i}=\delta$ is an impatient entrepreneur with a low discount factor and $\delta+\Delta$ is a patient entrepreneur with a high discount factor, with $\Delta>0$. The capitalist believes $p$ is the probability that $\delta_{i}$ equals $\delta+\Delta$ and that $(1-p)$ is the probability that $\delta_{i}$ equals $\delta$. Thus, $p$ corresponds to the proportion of patient entrepreneurs in the market. Only the entrepreneur knows his type $\delta_{i}$, however.

The contract between the capitalist and the entrepreneur stipulates if the activity will be financed, and, further, how the profit will be shared between the capitalist and the entrepreneur. It can be proven more rigorously that no positive transfer from the capitalist to the entrepreneur will be specified.

If the activity is successful, the two parties share the profit, $R$, such that $R_{L}$ goes to the capitalist and $R-R_{L}=R_{E}$ goes to the entrepreneur. The entrepreneur's limited liability implies that both sides will receive 0 in case of failure. The capitalist's claim can but need not be interpreted as debt. In fact, the outside financing can take the form of either debt or equity. ${ }^{4}$ For simplicity, however, we present the model only in terms of debt financing.

An entrepreneur of type $i$ will earn $\delta_{i} R_{E}$. The patient entrepreneur will earn discounted profit $(\delta+\Delta) R_{E}>\delta R_{E}$, with $0 \leq \delta+\Delta \leq 1$, if $I-A$ has been invested into the productive venture. Alternatively, the entrepreneur can behave destructively and misappropriate the investment of the capitalist. In this case, he keeps his assets $A$ and earns a destructive profit $\lambda(I-A)$ from the capitalist's investment. Here, $\lambda$ represents a specific, exogenously given institutional environment, for example, the quality of rule of law in a country. If $\lambda$ is high, a weak institutional climate allows a destructive entrepreneur to appropriate a high share of the capitalist's investment. A low $\lambda$ represents a stronger institutional environment, where destructive entrepreneurship is less profitable.

The zero profit constraint of the capitalist (e.g., due to competition) can be written as

$$
p R_{L}=I-A .
$$

The rate of interest $\mathrm{l}$ is implicitly given by

$$
R_{L}=(1+1)(I-A) .
$$

If the activity is not financed, the entrepreneur still holds his original assets $A$ and the capitalist still holds her original assets $I-A$. To make things interesting (and for many countries also more realistic), we assume that the two types of entrepreneurs also have different incentives. Consistent with our theory, these incentives are determined by the institutional conditions represented by $\lambda$. The strength of the 
institutional environment determines the benefits of selling/consuming the misappropriated assets as a fraction $\lambda$ of their original value, or, alternatively, the costs $(1-\lambda)$ of misappropriation. We thus assume that the patient entrepreneur prefers to invest the external capital into the productive venture, with $(\delta+\Delta) R_{E} \geq A+$ $\lambda(I-A)$, while the impatient entrepreneur prefers to behave destructively, because $\delta R_{E}<A+\lambda(I-A)$. Thus, the impatient entrepreneur will earn the destructive profit $\lambda(I-A)$.

This can be interpreted as economic inequality where one type needs the profits out of the project much earlier than the other, and in the extreme, right away by stealing them once invested. As an alternative to different discount factors, we could also assume that the two types of entrepreneurs expect different profits $\left(R_{\mathrm{hi}}\right.$ and $\left.R_{\mathrm{lo}}\right)$. For instance, one entrepreneur may be less skilled or educated and therefore expects a much lower profit $R$ from the venture than a more educated/skilled entrepreneur. Although it is not the discount factor that is heterogeneous, but the return $R$ (private knowledge to the entrepreneur) that entrepreneurs expect from the project, the results would be qualitatively similar.

Note that the entrepreneur's action is observable but not contractible. The contract is contingent on the project's return (under productive entrepreneurship), but the capitalist's investment $I-A$ is always assumed to be exposed to misappropriation once the contract is signed. This assumption depends on the institutional framework and may particularly apply to environments with weak institutions.

\section{The Capitalist Analysis}

In equilibrium, the capital will invest if

$$
\begin{gathered}
p R_{L} \geq I-A \\
p \geq \bar{p} \equiv \frac{I-A}{R_{L}} .
\end{gathered}
$$

With respect to the interest rate of the capitalist, we can define critical levels of $p$ and 1 as

$$
p \geq \tilde{p} \equiv \frac{1}{1+\imath} \Leftrightarrow \mathrm{\imath}>\tilde{\mathrm{\imath}} \equiv \frac{1}{p}-1 .
$$

Note that the participation constraint is always satisfied for both types of entrepreneurs, because of whatever the two types do (behaving productively or destructively), they always earn more than their reservation utility $A$.

Furthermore, the incentive compatibility constraint is never satisfied for both types if one of them is sufficiently impatient, because then $\delta R_{E}<A+\lambda(I-A)$, which incurs a loss for the capitalist. This loss cannot be prevented by increasing $R_{E}$ (reducing $R_{L}$ ), because the capitalist's zero-profit constraint (1) is assumed to be binding. 
Journal of Conflict Resolution 57(I)

In order to fund the project and earn a potential return $R_{L}$, the capitalist has to put her money at risk, because she cannot draft a contract protecting her investment from misappropriation by a very impatient entrepreneur. The capitalist also cannot specify a contract (or a menu of contracts) that leads to self-selection of the two types of entrepreneurs, because sufficiently impatient entrepreneurs would always accept the contract and always choose to behave destructively.

As long as $p<1$, there is some positive probability $(1-p)$ that the capitalist will invest and face a destructive entrepreneur. Reflecting perceived risk, the capitalist will ask for an interest rate based on the probability of meeting a patient versus an impatient entrepreneur. This situation demonstrates how the relationship between the capitalist and the entrepreneur can become embedded. On one hand, the higher the probability of meeting an impatient entrepreneur, the higher the interest rate charged by the capitalist. On the other hand, the higher the interest rate, the more accepting is the capitalist of impatient entrepreneurs in the market.

Note that as a necessary condition for financing the activity, the entrepreneur's assets are greater than $\bar{A}$ :

$$
I-p R_{L} \equiv \bar{A} \leq A .
$$

This condition corresponds to the established credit rationing models (see Holmstrom and Tirole 1997; Tirole 2006) that demonstrate that the entrepreneur needs to invest some level of necessary collateral $\bar{A}$ in order to receive any external investment. In equation (4), this critical level $\bar{A}$ is lower when the fraction $p$ of patient entrepreneurs in the market increases, or when the contractually specified loan to the capitalist increases.

In equation (4), this critical level $\bar{A}$ is also lower when the total investment necessary for the activity decreases. By substituting $R_{L}=R-R_{E}$ into equation (4), we can rearrange the condition to relate to the return on investment for the project ${ }^{5}$ :

$$
1-p\left(\frac{R}{I}-\frac{R_{E}}{I}\right)=\frac{\bar{A}}{I} \leq \frac{A}{I} .
$$

For the given investment $I$, a decrease in return on investment $R$ will increase the entrepreneur's necessary collateral $\bar{A}$. Therefore, in less profitable markets, capitalists will require entrepreneurs to provide higher collateral and tighten credit rationing. If the entrepeneurs are less able to access external financing, they can shift toward higher levels of impatience. This can, in turn, discourage capitalists from investing.

\section{The Entrepreneur Analysis}

In the following section, we derive the comparative static properties of the equilibrium conditions from the perspective of the entrepreneur. In order to observe productive and destructive entrepreneurship simultaneously, the following two conditions need to be satisfied in equilibrium: $(\delta+\Delta) R_{E} \geq A+\lambda(I-A)$ and $A+$ $\lambda(I-A)>\delta R_{E}$. From these conditions, we can conclude the following proposition: 
Proposition 1: For all $\bar{R}_{E} \geq R_{E} \geq \underline{R}_{E}$, productive and destructive entrepreneurship coexist in equilibrium, with

$$
\frac{A+\lambda(I-A)}{\delta} \equiv \bar{R}_{E}>\underline{R}_{E} \equiv \frac{A+\lambda(I-A)}{(\delta+\Delta)} \forall \Delta>0 .
$$

It follows that for all $R_{E} \geq \bar{R}_{E}$, there will be only productive entrepreneurship, since both types of entrepreneurs will prefer the profit from the productive activity. For $\underline{R}_{E} \geq R_{E}$, both types will prefer the profit from destructive entrepreneurship.

Thus, if returns from productive activities are very low, destructive entrepreneurship will dominate and will even be pursued by the more patient entrepreneurs. Above a certain level of project returns, however, it will be more profitable for patient entrepreneurs to behave productively, although impatient entrepreneurs will still be destructive unless an even higher level of productive returns is reached.

Next, we analyze how this interval is affected by changes in $\Delta$. It is straightforward to see that while $\bar{R}_{E}$ is independent of $\Delta, \underline{R}_{E}$ is a decreasing function of $\Delta$ :

$$
\frac{\partial \underline{R}_{E}}{\partial \Delta}=\frac{\partial\left(\frac{A+\lambda(I-A)}{(\delta+\Delta)}\right)}{\partial \Delta}=-\frac{(A-A \lambda+I \lambda)}{(\Delta+\delta)^{2}}<0 .
$$

This allows us to formulate the following proposition on the heterogeneity of entrepreneurs' with regard to their patience:

Proposition 2: The larger the difference $\Delta$ of the entrepreneurs' degree of patience, the larger the interval in which both forms of entrepreneurship coexist.

For arbitrary fixed vales of $A, I, \lambda$, and $\delta$, the following graph represents $\bar{R}_{E}$ and $\underline{R}_{E}$ as functions of the difference $\Delta$ of the entrepreneur's patience:

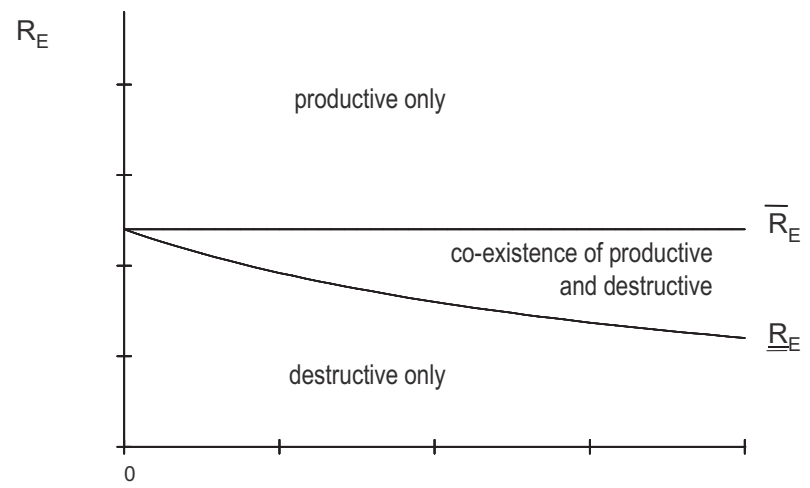


The interval for $R_{E}$, where productive and destructive entrepreneurship coexist, increases in the difference in patience between the two entrepreneurs. Concurrently, the interval for which only destructive entrepreneurship exists is decreasing. Intuitively, the patient entrepreneur's incentive to behave destructively is reduced, because his revenue from the activity increases with $\Delta$. As the impatient entrepreneur's incentives remain unchanged, the overall incentive to behave destructively decreases in $\Delta$.

Of course, the result that the interval, in which productive and destructive activities coexist, increases in $\Delta$, does not critically depend on the interpretation of $\Delta$ as the difference in entrepreneurs' patience. In principle, similar results can be produced by any other type-specific characteristics that affect $R_{E}$ in a similar manner and that motivate heterogeneous project returns across an entrepreneurial talent base. ${ }^{6}$

To analyze the effect of destructive entrepreneurship on social welfare, we first define welfare as the sum of all profits (i.e., of the capitalist, the productive entrepreneur, and the destructive entrepreneur). If parameters are such that there is only productive entrepreneurship, welfare will be given as

$$
R_{L}+p(\delta+\Delta) R_{E}+(1-p) R_{E} .
$$

Consider a situation in which the impatient entrepreneur is just indifferent between investing productively and disappropriating the capitalist's capital, thus $R_{E}=\bar{R}_{E}$. In this situation, we know that for any $R_{E}^{\prime} \leq \bar{R}_{E}$, the impatient entrepreneur will become destructive:

$$
(1-p) \delta R_{E}^{\prime} \leq(1-p)(A+\lambda(I-A))
$$

and hence

$$
\begin{aligned}
& R_{L}+p(\delta+\Delta) \bar{R}_{E}+(1-p) \bar{R}_{E} \\
& \geq R_{L}+p(\delta+\Delta) R_{E}^{\prime}+(1-p) R_{E}^{\prime} \\
& >p\left(R_{L}+(\delta+\Delta) R_{E}^{\prime}+(1-p)(A+\lambda(I-A))+(1-p) 0 .\right.
\end{aligned}
$$

The last inequality stems from the fact that even the smallest reduction in $R_{E}$ will, in equilibrium, lead to misappropriation of the capital with probability $(1-p)$. Thus, on the left-hand side, we have the first best solution for a given $R_{E}$, while on the right-hand side we have the equilibrium situation. Welfare reduction resulting from destructive entrepreneurship is thus captured by the difference in welfare in these two situations. Furthermore, we can add a term $(1-\eta)$ for the opportunity cost of the enforcement that is needed to recapture or protect the capitalist's investment. Intuitively, this is the foregone welfare from investing into, for example, law enforcement activities to recapture stolen assets or prevent destructive activities, instead of investing into alternative economic activities with higher welfare effects. Note that the misappropriated fraction $\lambda(I-A)$ is welfare neutral. Welfare-relevant 
opportunity costs of enforcement imply that the residual fraction of the capitalist's investment, $1-\lambda(I-A)$, is wasted to some degree $(1-\eta)$ and is not entirely flowing back to society (neglecting conservatively any positive externalities from the project on society):

$$
\begin{aligned}
& R_{L}+p(\delta+\Delta) R_{E}^{\prime}+(1-p) R_{E}^{\prime} \\
& >p\left(R_{L}+(\delta+\Delta) R_{E}^{\prime}+(1-p)((A+\lambda(I-A))+(1-\lambda)(\eta(I-A))\right. \\
& \Rightarrow R_{L}+\delta R_{E}^{\prime}>A+\lambda(I-A)+(1-\lambda) \eta(I-A) .
\end{aligned}
$$

Using $R_{L}=I-A$, the last inequality can be rearranged to

$$
\begin{aligned}
& I-A+\delta R_{E}^{\prime}>A+\lambda(I-A)+(1-\lambda) \eta(I-A) \\
& \Rightarrow(1-\eta)(1-\lambda)(I-A)+\delta R_{E}^{\prime}-A>0 .
\end{aligned}
$$

Interpreting this difference as the negative effect of the existence of destructive entrepreneurship on social welfare, we can conclude the following:

Proposition 3: The effect of destructive entrepreneurship on social welfare is negative. The negative effect of destructive entrepreneurship is the weaker, the higher A, $\eta$, and $\lambda$. Larger $\delta$ and $R_{E}$ increase (c.p.) the negative effects of destructive entrepreneurship.

Thus, the more entrepreneurs (patient or impatient) are able to invest their own capital into the joint project (i.e., the higher $A$ ), the smaller are the negative effects on welfare by destructive entrepreneurship. Intuitively, the wealthier entrepreneurs are, and the less dependent on capitalists external investments, the less the potential to (partially) destroy these funds $(I-A)$. Further, we find that the more patient both types of entrepreneurs are, the larger is the destructive impact on social welfare. This result is driven by the fact that investment returns increase in entrepreneurial patience, generating more profit and social welfare that can potentially be destroyed.

Proposition 3 also states that social welfare is decreasing in two institutional variables, $\lambda$ (absence of rule of law) as well as $\eta$ (proportion of assets that can be "saved" from total destruction). The greater the part of the misappropriated investment that can be saved from being entirely destroyed in the process, $\eta(1-\lambda)$ $(I-A)$, the higher the social welfare. Analogously, the weaker the rule of law, the more is the destructive entrepreneur able to consume (i.e., save) the misappropriated investment, $\lambda(I-A)$, which would otherwise be destroyed and wasted.

To provide more detail on the effects of the institutional environment and condition, we analyze how changes in the absence of rule of law $\lambda$ affect the interval where both destructive and productive entrepreneurship coexist in equilibrium. We first assume complete absence of rule of law. Comparative static properties show 
that both critical values $\bar{R}_{E}$ and $\underline{R}_{E}$ are increasing functions of $\lambda$ but that $\bar{R}_{E}$ increases with a larger slope:

$\bar{R}_{E}$ and $\underline{R}_{E}$ are increasing functions of $\lambda$, but that $\bar{R}_{E}$ increases with a larger slope:

$$
\frac{\partial \bar{R}_{E}}{\partial \lambda}=\frac{(I-A)}{\delta}>\frac{\partial \underline{R}_{E}}{\partial \lambda}=\frac{(I-A)}{(\Delta+\delta)}>0 .
$$

For arbitrary fixed values of $A, I, \delta$, and $\Delta$, the following graph represents $\bar{R}_{E}$ and $\underline{R}_{E}$ as functions of the change in rule of law $\lambda$ :

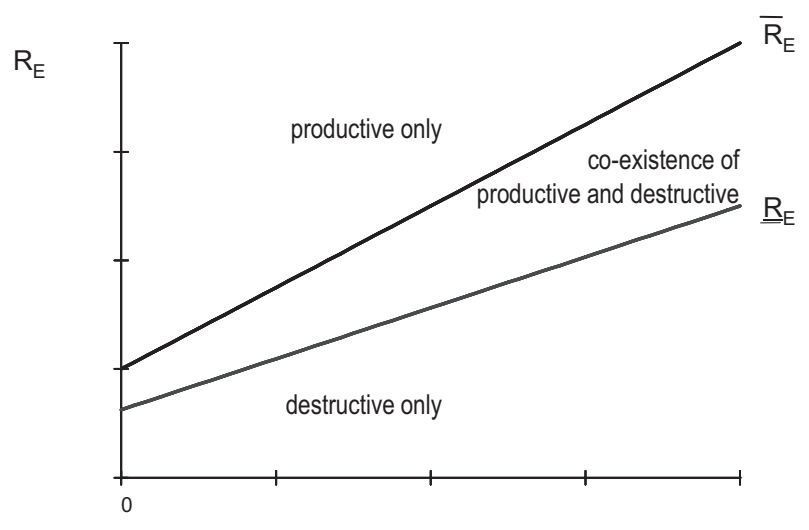

Absence of rule of law

We can summarize this in the following proposition:

Proposition 4: The interval for $R_{E}$, where productive and destructive entrepreneurship coexist, is increasing under weakened rule of law. The interval for destructive entrepreneurship is also increasing.

Intuitively, the weaker rule of law increases the share of the external investment that can be consumed. Accordingly, there is a greater incentive for both types of entrepreneurs to behave destructively, and there is lower incentive for capitalists to invest.

\section{Raiding}

Thus far, we assumed that only resources endogenously committed to the venture can be misappropriated. In this extension of the model, we include the possibility that the entrepreneur can also decide to raid resources not endogenously invested by the capitalist. In the model so far, destructive entrepreneurship referred to a situation where, for example, a capitalist decided to invest into a venture and the entrepreneur (partner in the venture) decided to either steal or misappropriate the committed funds and put them to suboptimal use (e.g., consume funds). The 
following extension also includes the case where the entrepreneur-instead of convincing the capitalist to fund a productive venture - simply raids the capitalist's funds and consumes them.

Thus, there are two ways that destructive entrepreneurship may occur. First, the entrepreneur can misappropriate the assets of the capitalist independently of the activity. The entrepreneur can engage in unproductive (redistributive) behavior and steal assets $\mu(I-A)$ from the capitalist for a payout of $\lambda \mu(I-A)$. Second, the entrepreneur can misappropriate the assets of the capitalist during or within the activity. Given this difference between forceful stealing outside and within the activity, we introduce $\mu$ as a distinct notation for the effectiveness of rule of law with regard to the proportion of the capitalist's assets that can be successfully raided. Analogously to the previous setting, $\lambda$ denotes the strength of the institutional environment with regard to the costs of raiding or the benefits of selling/consuming the raided assets.

This extension of our model incorporates the assumption of a "predator-prey" situation, which is employed in related models of conflict resolution and in the property rights literature (see Bates, Greif, and Singh [2002] and Skaperdas [1992]). In this situation, the investment consideration of the capitalist will be

$$
\begin{gathered}
p R_{L} \geq p(I-A)+(1-p)(1-\mu)(I-A) \\
p \geq \breve{p} \equiv \frac{(I-A)(1-\mu)}{R_{L}-\mu(I-A)} .
\end{gathered}
$$

In terms of the interest rate of the capitalist, we can also define the critical levels of $p$ and $\mathrm{l}$ as

$$
p \geq \hat{p}=\frac{1-\mu}{1+\imath-\mu} \Leftrightarrow \mathrm{\imath} \geq \hat{\imath} \equiv \frac{(1-\mu)(1-p)}{p} .
$$

A comparison to the threshold level $\tilde{\mathrm{l}}$ of the capitalist's interest rate as defined in equation (3) of the preceding analysis reveals that $\hat{\imath}<\tilde{i}$ :

$$
\hat{\imath}<\tilde{\imath} \text { if } \frac{(1-\mu)(1-p)}{p}<\frac{1}{p}-1 \Leftrightarrow(1-\mu)(1-p)<1-p \quad \forall \mu>0 .
$$

The minimal interest rate that the capitalist demands will be lower if the entrepreneur can raid (part of) her assets. Intuitively, the threat of raiding idle assets reduces the expected value of not investing for the capitalist. If the capitalist understands this, then she still has an incentive to invest in otherwise unattractive activities, since the return still exceeds her expected costs of being raided.

Similarly, a comparison to the threshold level $\bar{A}$ of assets as defined in equation (4) reveals that $\hat{A}<\bar{A}$ :

$$
I-\frac{p}{(1-(1-p) \mu)} R_{L} \equiv \hat{A}<A
$$




$$
\hat{A}<\bar{A} \text { if } \frac{p}{(1-(1-p) \mu)}>p \Leftrightarrow 0>-(1-p) \mu \quad \forall \mu>0 .
$$

Hence, the critical level of assets (collateral) required from the entrepreneur is lower if the entrepreneur can raid the capitalist. If all entrepreneurs would behave destructively, capitalists cannot protect their assets by not investing them. This is different to the previous setting without raiding, where capitalists can protect their assets simply by not investing into projects. Although raiding is an extreme form of destructive entrepreneurship and as such represents a special case in our more general model of destructive entrepreneurship (refer to Sanders and Weitzel [2013] for a detailed analysis of raiding by potential entrepreneurs), it is particularly relevant in regions with very weak institutions and/or conflict.

\section{Institutions and Incentives}

It follows from our model that institutions are central drivers of entrepreneurial talent. Entrepreneurs are motivated to make selections based on expected rewards - that is, their incentives come out of their institutional constraints. The integral role of reward structures in determining activity has been discussed at length (Baumol 1990; Murphy, Shleifer, and Vishny 1991; Acemoglu 1995; Grossman and Kim 1995) and typically centers on the trade-off between productive and unproductive forms. Despite divergence on whether reward structures are initially shaped endogenously or exogenously, ${ }^{7}$ they always have the potential to become endogenous due to path dependence (for more, see Nunn 2007). This means reward structures are not only critical determinants of the current allocation of entrepreneurial activity but also potential determinants of future reward structures (see Acemoglu 1995). Endogeneity in institutions can arise from the relationship between economic and political systems (see Acemoglu and Johnson 2005). Entrepreneurs can also directly and indirectly affect institutions through gains of political power (for more, see Douhan and Henrekson 2008a). This is one of the many ways through which they may be able to destroy inputs. Endogenous institutions pose a problem when incentives do not favor productive entrepreneurship and particularly when they favor destructive entrepreneurship.

Entrepreneurs are heterogeneous for many reasons - among them is the range of conditions under which they operate. This can lead to the persistence of destructive entrepreneurship both as a one-time outcome under weak rule of law and as an equilibrium outcome under persistently weak rule of law (see Proposition 4). Conditions can vary by country, region, state, and local context. For this reason, destructive entrepreneurship can become an equilibrium outcome (see Douhan and Henrekson 2008a \& b; Desai 2008). First, individuals may respond to incentives with high time preference. An entrepreneur may be willing to sacrifice future returns for lower returns today. If he makes a utility calculation of expected gains and losses ${ }^{8}$ and 
is not confident about transactions tomorrow, he will place a higher premium on what is possible today. As our model shows, the high discounting of future (productive) returns can lead to destructive behavior, despite the fact that these entrepreneurs have the talent to be productive. Of course, the destructive effects are marginal when this applies to only one entrepreneur as implied by our two-player game. However, multiple entrepreneurs not only have a much greater cumulative economic effect but may also negatively influence the present value of potential future returns (each other's discount rates), because of the generally increased destructive activity in a country. Thus, in a dynamic setting, the long-run equilibrium tendency under conditions of uncertain political economy is likely to be toward destructive entrepreneurship if there are a sufficient number of impatient entrepreneurs.

\section{Implications and Conclusion}

We provide this model of destructive entrepreneurship in an attempt to explain the concept and advance a more comprehensive understanding of the range of entrepreneurial activities. Our model yields important directions in four research agendas as well as critical insights and implications for policy.

\section{Research Agendas}

First, significant theoretical work is necessary to understand how destructive entrepreneurship can be both a process and an outcome (see Douhan and Henrekson 2008). This is related to occupational choice or the lack thereof, in countries with uncertain political and economic conditions. In many countries, destructive activities may result from necessity. An important question for further theoretical work is on the dynamics of raiding, and if resulting suboptimal investments themselves can become embedded (see Sanders and Weitzel 2013).

Second, although the literature on entrepreneurial allocation and its underlying determinants is growing, the specific dynamics, causes, and effects of destructive entrepreneurship remain understudied. Incentives and institutions are increasingly studied with respect to transforming and strengthening economies, this can be greatly enhanced by first extending and clarifying the "furthest point" on the spectrum: destructive entrepreneurship. For example, could an optimal balance of institutions exist (Acemoglu and Verdier 1998) to discourage entrepreneurial talent from allocating to undesirable activities? How can deeper insight on historic processes of institutional existence and change (see Greif and Laitin 2004) shed light on modern drivers? In this line, country- or region-focused empirical research may yield important insights on the drivers of destructive entrepreneurship.

Both the preceding research agendas ultimately lead to important empirical questions, such as measuring the share of destructive entrepreneurship as compared to other forms of entrepreneurship as well as assessing specific inputs or 
Journal of Conflict Resolution 57(I)

endowments. The importance and difficulty of undertaking empirical research on this subject should not be underestimated.

A third related research agenda concerns the temporal dimension. Essentially, destructive entrepreneurship and its share of total entrepreneurial activity may vary not only according to country-specific factors but also according to the level and timing of economic development. Perhaps entrepreneurial allocation changes along with population or demographic trends. Perhaps the allocation of entrepreneurship varies along an interaction of time and political context. For example, is destructive entrepreneurship greatest in the five years immediately after the introduction of reforms or is it lowest at this point? Understanding the potential relevance of time may shed light on the drivers and outcomes of destructive entrepreneurship and may contribute to knowledge on the evasive institutional lag in transition economies.

Fourth, direct delineation from this theory is in research on conflict and political instability, where there are many potential research questions. We consider this research agenda the most promising extension of our model. As civil conflict and terrorism are both increasingly recognized to have roots in economic factors, the potential of entrepreneurship both to help and to hinder stability is key. For example, how does destructive entrepreneurship affect political stability in regions where different types of scarcity (see Homer-Dixon 1997) feed into conflict? Does the allocation of entrepreneurship differ according to different constraints in a region? To what extent are terrorist activities, including financing, the results of incentives for destructive entrepreneurship versus ideologically motivated events? The link between factors related to political stability ${ }^{9}$ and the allocation of entrepreneurial talent is a ripe and open area for research. A related question concerns the effect of terrorism on investment behavior of different economic actors, such as selfemployed farmers (see Singh 2012). Gross domestic product losses up to 60 percent during a typical conflict (see Collier et al. 2003) could be driven in part by the shift from productive and unproductive activities to destructive activities. As traditional attempts to support postconflict countries have not always achieved the intended results, supporting entrepreneurship offers a great deal of promise if it can be productive. Empirical research on firms in conflict is growing and is an important area of inquiry (see, for example, Collier and Duponchel [2012] and Camacho and Rodriguez [2012]). In addition, the role of informal institutions may be especially important where conflict is marked by state failure and market failures. A key question is what institutions exert the greatest influence or offer the most opportunity for gains from change?

\section{Policy Implications}

In addition, our model has implications for the practice of economic development across institutional context. In developing countries, some policies on entrepreneurship have focused on how to increase the share of formal businesses in the economy-both through supporting the establishment of new businesses and through 
formalization of existing businesses. Our model adds nuances to support a more comprehensive understanding of activities outside those which can be formalized. Destructive entrepreneurship may be a larger proportion of total entrepreneurial activity within a single economy than currently understood: our model proposes that it coexists with productive entrepreneurship but the actual distribution of activities remains an open question. This leads to a question more evasive than that of how to encourage formal entry among private firms: What is the actual distribution of activities between unproductive and destructive entrepreneurship? A second question is, how relevant is formality to productive entrepreneurship versus to unproductive and destructive entrepreneurship? Knowing about formal or informal status does not necessarily allow us to infer about impact. For example, substantial numbers up to 60 percent of the Asian workforce operate in the informal sector (International Labour Organization [ILO] 2007), but this information does not allow us to infer much about the nature of their activities. This has a critical policy implication because it leaves policy makers with little knowledge about actual effects on the economy. The nature of activity should be properly understood before attempts at transformation can succeed. In other words, two countries with the same productive allocation (say, 50 percent) may have vastly different allocations of unproductive and destructive activities in the remaining 50 percent. In addition, policies aimed at formalizing existing informal business may not be effective in mitigating destructive entrepreneurship, which could include illegal activities. For example, people engaged in informal, illegal business operations are unlikely to be reached through policies aimed at formal entry due to the nature of their activities. Economic development policy can thus be refined and made more effective with insight on the nuances of allocation.

Policy applications are particularly important in the context of conflict. In countries hosting conflict or recovering from conflict, the formal sector may shrink. This may be the result of state predation over time or response to institutional collapse. In this context, two specific situations can benefit from policy direction. First, countries undergoing current conflict, long-term insurgent or recurring terrorist activity, or transition of political regime, may be better equipped for conflict management and the process of stabilization by leveraging effective economic development policies. Second, one of the major challenges in economic development, postconflict reconstruction (Wolfensohn 1999), is further complicated by the endogenous nature of institutions where destructive entrepreneurship may easily become institutionalized.

Attempts to predict conflict (see Gurr [1994] for a discussion) may also benefit from our model. Knowledge about destructive entrepreneurship may be useful in early warning systems and conflict prevention efforts. Attempts at early warning consider a combination of factors, which, with the right magnitude and at the right time, can culminate in conflict. The contributions from using existing economic measures (e.g, macroeconomic factors, Gini index, measures of inequality, and measures of poverty and underdevelopment) can benefit from insight on destructive entrepreneurship, as it is reflective both of institutional pressures and resulting 
economic decision making. For example, tracking the allocation of entrepreneurship over time may reveal the state of stability and how broader changes (e.g., changes in leadership and political representation) may directly affect economic activity. The speed at which the shares of productive and destructive entrepreneurship expand or contract could be useful in the design of future early warning systems. Thus, monitoring the allocation of entrepreneurship regularly may be an important tool for conflict prevention, particularly when it can be matched with other trends such as poverty, employment, and labor trends.

Understanding how to balance the drivers of destructive entrepreneurship may help enable more effective governance and contributions from economic development policy to both the process and outcomes of stabilization. Time may be a key element. If the incentives for destructive entrepreneurship are likely to be stronger in the presence of high time preference, then part of the move toward stability may include policies aimed at increasing the patience of entrepreneurs. This can be anything from a basic income grant or food aid to rudimentary financial instruments that support entrepreneurs in waiting for the medium- and long-term proceeds of productive projects, thus preventing them from behaving destructively by consuming productive assets in the short run. A basic income grant, for example, is a type of social security payment to provide for individual basic human needs. ${ }^{10}$ An example from the opposite end of the spectrum of development policies are improvements in often very rudimentary financial markets and risk management, for example, through offering (easier access to) export insurances, hedging of commodity price, or exchange rate risks but also by generally increasing the efficiency of formal and even informal financial transactions. All of these policies can help reduce the discount that entrepreneurs put on their share of future returns, making productive behavior more attractive than the destructive alternative.

Another related example of policies designed around time preference is specific to conflict and postconflict areas - that is, the opportunity to commence reintegration programs concurrently with disarmament programs, rather than a traditional (sequential) approach. Short-term programs to supplement or provide incomes directly to special populations, such as displaced persons or at-risk persons, may be appropriate ways to support stability while working toward longer-term policies (such as training or transitioning into employment). While the income provided in these programs may be used directly for consumption, it can reduce the pressure for income (and increase patience), thereby weakening incentives for participation in destructive activities (such as crime, violence, or insurgency). Such programs may ease the path to longterm, sustained economic recovery, so long as they are designed and implemented as short-term support. Related to our section on raiding, if youth contribute to instability by undertaking destructive activities, why wait until peace is imposed to find ways for productive economic integration? Providing alternatives for combatants while conflict is ongoing may provide incentives that bolster stabilization efforts.

Thus, a value addition of our model is it serves as a platform to connect modern economic realities with economic development planning and policies. The rapidly 
evolving state of international economic and political relations calls for policy approaches that can be responsive to the effects of globalization and spillovers: money, people, finance, technologies, and ideas move and respond quickly to institutional changes. The existence of entire regions of instability demonstrates the importance of sound policy. Our model presents a nuanced way to understand economic development, constant change, and important contextual differences in developing countries. For example, there are important distinctions between the needs and allocation of entrepreneurship in India versus Afghanistan. Our model is relevant for countries that are both poor and unstable and allows the constraints in a particular economy to be examined. In particular, our model can help explain the apparent mutually reinforcing relationship between poverty and political instability in low-income countries, ${ }^{11}$ many of which have hosted major conflict since 1980 (Wolfensohn 1999).

Our model can enhance understanding of economic activity across institutional contexts. Although the implications are perhaps more clear for economies hosting or recovering from conflict, destructive entrepreneurship certainly occurs in countries across levels of development. In developed countries, the lines between unproductive and destructive entrepreneurs may be less obvious, although the latter do exist and can produce significant economic damage, as corporate scandals like Enron and the financial industry have repeatedly shown. In developing countries, the trade-off between unproductive and destructive entrepreneurship is perhaps more obvious but still underresearched. Here, the gains from understanding and measuring destructive entrepreneurship are high. As we have seen from our model, the interaction between entrepreneurs and capitalists can become a relationship embedded with incentives favoring destructive entrepreneurship. The movement of entrepreneurial talent and destructive entrepreneurship is an urgent question in research and public policy - a question that can provide relevance on multiple fronts.

\section{Acknowledgments}

We thank William Baumol, Stephanie Rosenkranz, Roger Stough, Frank Gunter, Wim Naudé, Johan Eklund, David Audretsch, Terrence Lyons, Mark Sanders, Mirjam van Praag, Simon Parker, Vishvanath Desai, Alex Acs, Michael Fritsch, Diemo Urbig, Sara Reeves, and Mehmet Demircioglu for comments and discussion. The authors are grateful to UNUWIDER for research support; Sameeksha Desai is grateful to the Kauffman Foundation and Max Planck Institute of Economics for research support. We thank participants of the Ratio Institute Colloquium for Young Social Scientists, seminars at the Max Planck Institute of Economics, the UNU-WIDER research workshop on conflict and entrepreneurship, and two anonymous referees for helpful comments.

\section{Declaration of Conflicting Interests}

The authors declared no potential conflicts of interest with respect to the research, authorship, and/or publication of this article. 


\section{Funding}

The authors disclosed receipt of the following financial support for the research, authorship, and/or publication of this article: the authors acknowledge financial support from UNUWIDER.

\section{Notes}

1. Murphy, Shleifer, and Vishny (1991) and Baumol (1990) describe similar concepts: Murphy, Shleifer, and Vishny's (1991) discussion of "entrepreneurship" and "rentseeking" parallels Baumol's (1990) discussion of "productive entrepreneurship" and "unproductive entrepreneurship."

2. A key question concerns people that are not free to choose due to structural or other barriers. Some models assume that individuals can choose between entrepreneurship and wage employment. However, very real constraints exist on individual occupational choice (see Ghatak and Jiang 2002) and, thus, on entrepreneurship, particularly in developing countries. Murphy, Shleifer, and Vishny note that "when they are free to do so [emphasis added], people choose occupations that offer them the highest returns on their abilities" $(1991,503)$. In addition, existing models of entrepreneurship may be appropriate for high-growth and high-technology sectors but simply may not fit many activities in poor, underdeveloped, and/or politically unstable countries.

3. Throughout this article, we follow the convention in principal-agent models that the gender of one player (here the entrepreneur) is male and the other player (here the capitalist) is female.

4. For instance, if the profit is 5, the capitalist's share of 1 can be interpreted either as a claim from 20 percent ownership or as a claim from risky debt with a nominal value of 1 . Analogously, a 10 percent return on investment for the capitalist can be interpreted either as an interest rate on debt or as a return of an equally risky equity investment.

5. Or, the capital intensity if $I$ is interpreted as capital requirements for the activity.

6. These may be different levels of training, different levels of education, skills, market access, supportive networks, or any other factor that systematically produces heterogeneous project returns across the entrepreneurial talent base.

7. Refer to Acemoglu (1995) and Baumol (1990) for more on how reward structures are shaped, endogenously or exogenously.

8. For a useful related discussion about utility calculations, see Macculloch (2005).

9. See Goldstone (2001) for more on factors related to political instability.

10. Although such an unconditional grant may go toward immediate consumption and not direct support for an entrepreneurial activity, it may help to reduce the urgency for immediate funds, thereby increasing the present value of productive returns if the opportunity arises. This may help prepare entrepreneurial talent to approach opportunities productively. Preliminary empirical evidence for this kind of program comes from Namibia, where a large-scale pilot project with a basic income grant (BIG) was started in 2004 (with 100 Namibian dollars per person per month). According to a study of the pilot project, the percentage of those able to get a job or become successfully self-employed increased 
from 44 percent to 55 percent while crime rates fell by 42 percent. A growth in non-BIG income per capita, from $\mathrm{N} \$ 118$ to $\mathrm{N} \$ 152$, may indicate the start of a demand-induced economic growth cycle. Also, school attendance increased, and there were no indications that alcohol-abuse has worsened (BIG Coalition 2009).

11. For a detailed discussion of this relationship, see Collier and Hoeffler (1998).

\section{References}

Acemoglu, Daron. 1995. "Reward Structures and the Allocation of Talent." European Economic Review 39:17-33.

Acemoglu, Daron, and Simon Johnson. 2005. "Unbundling Institutions." Journal of Political Economy 113:949-95.

Acemoglu, Daron, and Thierry Verdier. 1998. "Property Rights, Corruption and the Allocation of Talent: A General Equilibrium Approach.” The Economics Journal 108:1381-403.

Bates, Robert, Avner Greif, and Smita Singh. 2002. "Organizing Violence." Journal of Conflict Resolution 46:599-628.

Basic Income Grant Coalition. 2009. "Making the Difference! The BIG (Basic Income Grant) in Namibia." Basic Income Grant Pilot Project Assessment Report. Accessed March 7, 2011. www.bignam.org.

Baumol, William. 1990. "Entrepreneurship: Productive, Unproductive and Destructive." Journal of Political Economy 98:893-921.

Bhagwati, Jagdish. 1982. "Directly Unproductive, Profit-Seeking (DUP) Activities.” Journal of Political Economy 90:988-1002.

Bowen, Harry P., and Dirk De Clercq. 2008. "Institutional Context and the Allocation of Entrepreneurial Effort." Journal of International Business Studies 39:747-67.

Camacho, Adriana, and Catherine Rodriguez. 2012. "Firm Exit and Armed Conflict in Colombia." Journal of Conflict Resolution.

Collier, Paul, and Marguerite Duponchel. 2012. "The Economic Legacy of Civil War: FirmLevel Evidence from Sierra Leone." Journal of Conflict Resolution.

Collier, Paul, V. L. Elliott, Havard Hegre, Anke Hoeffler, Marta Reynal-Querol, and Nicholas Sambanis. 2003. Breaking the Conflict Trap: Civil War and Development Policy. Washington, DC: The World Bank and Oxford University Press.

Collier, Paul, and Anke Hoeffler. 1998. "On the Economic Causes of Civil War." Oxford Economic Papers 50:563-73.

Desai, Sameeksha. 2008."Essays on Entrepreneurship and Postconflict Reconstruction." Doctoral diss., George Mason University: Virginia.

Douhan, Robin, and Magnus Henrekson. 2008a. "The Political Economy of Entrepreneurship: An Introduction." In The Political Economy of Entrepreneurship Volumes I and II, edited by Magnus Henreksonand Robin Douhan, xi-xxxi. Douhan Cheltenham, UK: Edward Elgar.

Douhan, Robin, and Henrekson, Magnus. 2008b. "Productive and Destructive Entrepreneurship in a Political Economy Framework," Working Paper Series 761, Research Institute of Industrial Economics. 
Journal of Conflict Resolution 57(I)

Ghatak, Maitreesh, and Neville Nien Huei Jiang. 2002. "A Simple Model of Inequality, Occupational Choice, and Development." Journal of Development Economics 69:205-26.

Goldstone, Jack 2001. "Demography, Environment and Security." In Environmental Conflict, edited by Paul Diehland Nils Petter Gleditsch, 84-108. Boulder, CO: Westview.

Greif, Avner, and David Laitin. 2004. "A Theory of Endogenous Institutional Change." American Political Science Review 98:633-52.

Grossman, Herschel I., and Minseong Kim. 1995. "Swords or Ploughshares? A Theory of the Security of Claims to Property." Journal of Political Economy 103:1275-89.

Gurr, Ted R. 1994. "Peoples Against States: Ethnopolitical Conflict and the Changing World System: 1994 Presidential Address." International Studies Quarterly 38:347-77.

Holmstrom, Bengt, and Jean Tirole. 1997. "Financial Intermediation, Loanable Funds, and the Real Sector." The Quarterly Journal of Economics 111:663-91.

Homer-Dixon, Thomas. 1997. Environment, Scarcity and Violence, Princeton, NJ: Princeton University Press.

International Labour Organization (ILO). 2007. “In Asia Informal Work Shifts But Remains Massive.” Accessed April 12, 2012. http://www.ilo.org/global/about-the-ilo/press-andmedia-centre/insight/WCMS_083603/lang-en/index.htm.

Macculloch, Robert J. 2005. "Income Inequality and the Taste for Revolution," The Journal of Law and Economics 48:93-123.

Murphy, Kevin, Andre Shleifer, and Robert Vishny. 1991. "The Allocation of Talent: Implications for Growth." Quarterly Journal of Economics 106:503-30.

Murphy, Kevin, Andre Shleifer, and Robert Vishny. 1993. "Why is Rent-Seeking So Costly to Growth?" The American Economic Review 83:409-14.

Nunn, Nathan. 2007. "Historical Legacies: A Model Linking Africa's Past to Its Current Underdevelopment." Journal of Development Economics 83:157-75.

Sanders, Mark, and Utz Weitzel. 2013. "Misallocation of Entrepreneurial Talent in Post conflict Environments." Journal of Conflict Resolution 57:41-64.

Singh, Prakarsh. 2012. "Impact of Terrorism on Investment Decisions of Farmers." Journal of Conflict Resolution.

Skaperdas, Stergios. 1992. "Cooperation, Conflict and Power in the Absence of Property Rights." American Economic Review 82:720-39.

Sobel, Russell. 2008. “Testing Baumol: Institutional Quality and the Productivity of Entrepreneurship." Journal of Business Venturing 23:641-55.

Tirole, Jean. 2006. The Theory of Corporate Finance, Princeton, NJ: Princeton University Press.

Urbig, Diemo, Utz Weitzel, Stephanie Rosenkranz, and Arjen van Witteloostuijn. 2012. "Exploiting Opportunities at all Cost? Entrepreneurial Intent and Externalities." Journal of Economic Psychology 33:379-93.

Weitzel, Utz, Diemo Urbig, Sameeksha Desai, Mark Sanders, and Zoltan Acs. 2010. "The Good, The Bad, and The Talented: Entrepreneurial Talent and Selfish Behaviour." Journal of Economic Behavior and Organization 76:64-81.

Wolfensohn, James. 1999. "Entering the 21st Century: The Challenges for Development." Philosophical Transactions: Biological Sciences 354:1943-48. 